\title{
Fluoride concentration in ground water and prevalence of dental fluorosis in Ethiopian Rift Valley: systematic review and meta-analysis
}

\author{
Habtamu Demelash $^{1 *}$ (D, Abebe Beyene ${ }^{2}$, Zewdu Abebe $^{3}$ and Addisu Melese ${ }^{4}$
}

\begin{abstract}
Background: The concentration of fluoride in ground drinking water greater than the world health organization standard value imposes a serious health, social and economic problem in developing countries. In the Ethiopian Rift Valley where deep wells are the major source of drinking water, high fluoride level is expected. Though many epidemiological studies on fluoride concentration and its adverse effects have been conducted in the region, the result is highly scattered and needs systematically summarized for better utilization.

Objective: This research is aimed at estimating the pooled level of fluoride concentration in ground drinking water and the prevalence of dental fluorosis among Ethiopian rift valley residences.

Methods: Cochrane library, MEDLINE/PubMed and Google scholar databases were searched for studies reporting the mean concentration of fluoride in ground water and prevalence of dental fluorosis in Ethiopian Rift valley. Search terms were identified by extracting key terms from reviews and selected relevant papers and review medical subject headings for relevant terms.

Results: The mean fluoride level in ground water and the prevalence of dental fluorosis were pooled from eleven and nine primary studies conducted in Ethiopian Rift Valley respectively. The pooled mean level of fluoride in ground water therefore was $6.03 \mathrm{mg} / \mathrm{l}(95 \% \mathrm{Cl} ; 4.72-7.72, p<0.001)$ and the pooled prevalence of dental fluorosis among residents in Ethiopian rift valley was 32\% (95\% Cl: 25, 39\%, $p<0.001), 29 \%$ (95\% Cl: 22, 36\%, p < 0.001$)$ and $24 \%$ ( $95 \%$ Cl: 17, 32\%, $p<0.001$ for mild, moderate and sever dental fluorosis respectively. The overall prevalence of dental fluorosis is $28 \%(95 \% \mathrm{Cl}, 24,32 \%, \mathrm{p}<0.001)$.

Conclusions: Though, the concentration level varies across different part of the rift valley region, still the level of fluoride in ground drinking water is greater than the WHO standard value $(1.5 \mathrm{mg} / \mathrm{l})$. Relatively high-level pooled prevalence of dental fluorosis was also seen in Ethiopian rift valley. Therefore, further studies covering the temperature, exposure time and other intake path ways with large sample size is recommended. Interventional projects should be implemented to decrease the concentration of fluoride in the ground drinking water source.
\end{abstract}

Keywords: Dental fluorosis, Fluoride, Concentration, Rift Valley, Ethiopia

\footnotetext{
* Correspondence: enyew29@gmail.com

${ }^{1}$ College of Health Sciences, Department of Public Health, Debre Tabor

University, Debre Tabor, Ethiopia

Full list of author information is available at the end of the article
}

(c) The Author(s). 2019 Open Access This article is distributed under the terms of the Creative Commons Attribution 4.0 International License (http://creativecommons.org/licenses/by/4.0/), which permits unrestricted use, distribution, and reproduction in any medium, provided you give appropriate credit to the original author(s) and the source, provide a link to the Creative Commons license, and indicate if changes were made. The Creative Commons Public Domain Dedication waiver (http://creativecommons.org/publicdomain/zero/1.0/) applies to the data made available in this article, unless otherwise stated. 


\section{Background}

Fluoride is one of among chemicals that has been shown to cause significant effects in people through drinking-water [1, 2]. It could enter the human body through the ingestion of food, drinking water, inhalation and dermal contact. However, drinking water is the most important exposure pathway of fluoride, as about $75-90 \%$ of fluoride intake [2, 3]. At its low concentrations in drinking-water, fluoride has beneficial effects on teeth development, but excessive exposure (greater than the WHO guideline value of $1.5 \mathrm{mg} / \mathrm{l}$ ), can give rise to a number of adverse effects [4-6]. The health effect ranges from mild dental fluorosis to crippling skeletal fluorosis as the level and period of exposure increases [4, 7]. Dental fluorosis is a developmental disturbance of dental enamel, caused by successive exposures to high level of fluoride during tooth development $[2,8]$.

Although, the world health organization has set the fluoride guideline limit of $1.5 \mathrm{mg} / \mathrm{l}$ in drinking water, Over 260 million people globally are drinking water from sources with high fluoride concentrations [9]. The ground water fluoride concentration is severe in countries within East African Rift Valley like Tanzania, Kenya and Ethiopia. The highest fluoride concentration reported $2800 \mathrm{mg} / \mathrm{l}$ in Lake Nakuru in Kenya [4]. Like other African countries situated in Rift Valley, fluoride is also a major health problem for communities using ground water sources in the Ethiopian Rift valley area [3, 10-12]. Nearly 8 million people in the Ethiopian Rift Valley are drinking from high fluoride water sources [7]. Long-term use of high fluoride drinking water is known to cause both dental and skeletal fluorosis observed in populations residing in the Rift valley $[2,13,14]$. Several studies in African countries, including Tanzania, Sudan, Nigeria and Kenya have found a high prevalence of dental fluorosis among populations that consume drinking water with high fluoride content $[4,13$, 15]. High fluoride concentration in ground water resulted high prevalence of dental fluorosis in the Ethiopian Rift Valley $[7,11,12]$ which has lifelong health impacts ranged from loss of teeth to debilitating pain [7, 16]. About 13 million people also thought to be at risk of developing fluorosis in this region [3].

Many researchers tried to investigate the mean concentration of fluoride in ground drinking water sources and prevalence of dental fluorosis in Ethiopian rift valley. But these studies are highly scattered and need systematically reviewed and summarized for better utilization. Therefore, this research work aimed at filling this gap through calculating the pooled mean level of fluoride concentration in ground drinking water sources and prevalence of dental fluorosis among Ethiopian rift valley residences.

\section{Objectives}

The objective of this systematic review and metaanalysis is to determine the level of pooled mean fluoride concentration in ground drinking water sources and the pooled prevalence of dental fluorosis in Ethiopian rift valley.

\section{Methods and materials \\ Study area}

The Ethiopian sector of the East African Rift system extends for more than $1000 \mathrm{~km}$ in a north east-south west to north- south direction from the Afar depression, at Red Sea-Gulf of Aden junction, southwards to the Turkana depression. It is a long and narrow strip of lowlying plain land in between the highlands. It stretches from the north eastern part of the country to the southern border with Kenya, and divides the highland masses into two, the central and eastern highlands of Ethiopia [4]. Groundwater is an important source of drinking water and the dominant source for domestic supply in the region where surface waters are scarce and seasonal [17-19]. This area of the country usually associated with high level of fluoride in groundwater because of volcanic and basaltic rocks, which are more likely to release a high concentration of fluoride $[10,17,20]$.

\section{Data sources and search strategy}

Peer reviewed journal articles which have reported the mean concentration of fluoride in ground water source and prevalence of dental fluorosis in Ethiopian Rift valley were searched via scientific databases, libraries and the journals themselves. Cochrane library, MEDLINE/ PubMed and Google scholar databases were the main sources for the studies. The Preferred Reporting Items for Systematic Reviews and Meta-Analyses (PRISMA) statement guideline [21] was used to screen articles (Fig. 1). The following searching terms with Boolean operators were used to search PubMed; fluoride OR f-OR fluorosis OR drinking AND water OR ground AND water AND rift valley AND Ethiopia. In addition, we tried to check references of searched papers to obtain additional articles which is not identified in the databases.

\section{Inclusion and exclusion criteria}

This review included all studies which measured the concentration of fluoride in ground drinking water sources and its outcome indicative (dental fluorosis) in Ethiopian rift valley region. Studies reported fluoride concentration (the minimum, maximum, mean and standard deviation in $\mathrm{mg} /$ l) were considered. In addition, the daily water consumption and fluoride intake per body weight also extracted from some studies. Regarding dental fluorosis, articles were selected based on fluorosis report with different severity level (mild, moderate and sever). Studies published in full text or abstract and published only in the English language (to avoid mistakes in the translation process) were included. Peer-reviewed and laboratory-based works with clear report 


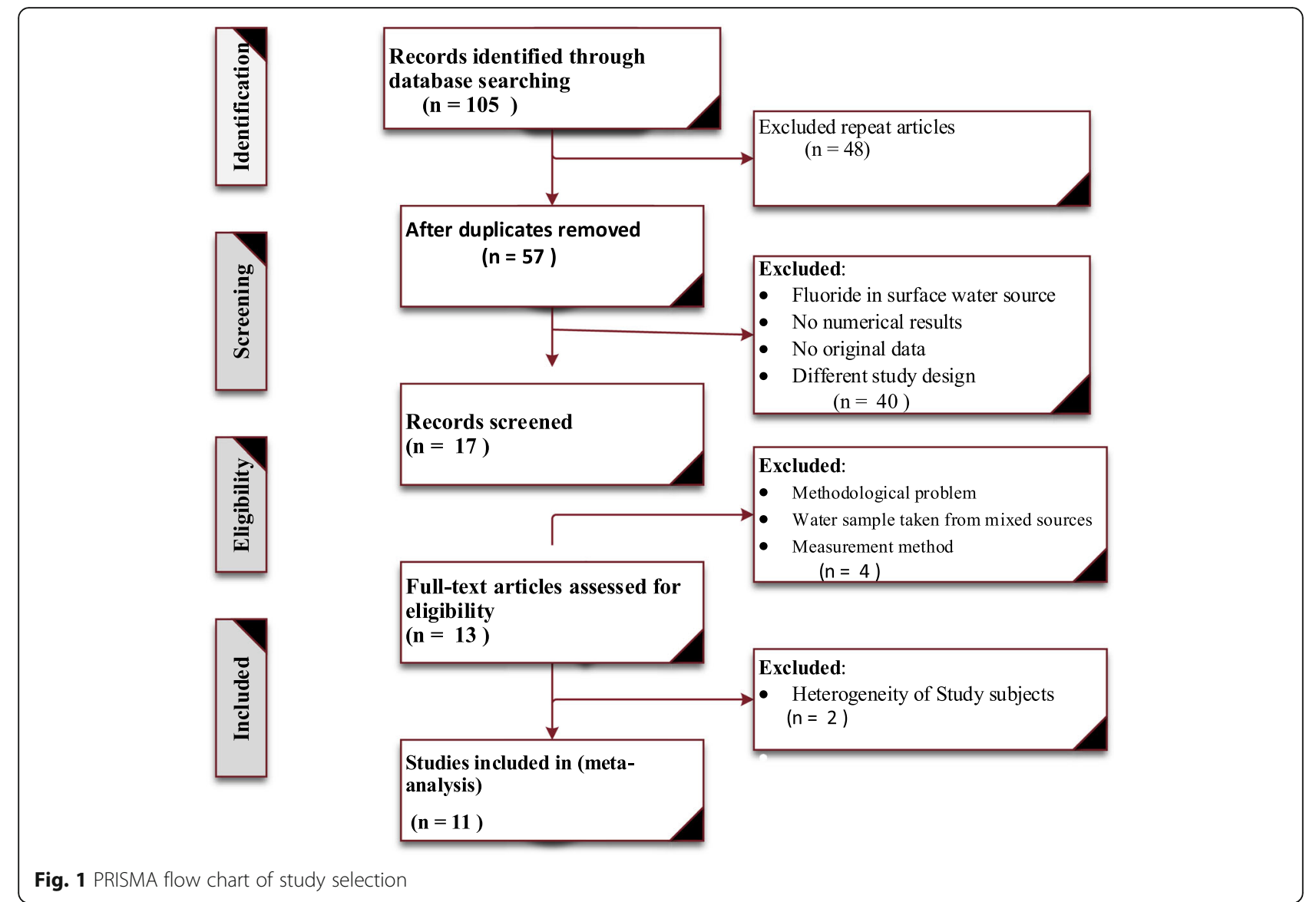

of the result of laboratory tests also considered during screening (Table 1). All articles which did not meet the proposed criterion were excluded.

\section{Quality assessment}

In order to assess the quality of included studies, the Newcastle-Ottawa Scale (NOS) which is adapted for crosssectional studies (additional file 1) was used. Four investigators (HD, AB, ZA and AM) assessed the quality of included studies based on the efforts made by the authors of each primary studies to minimize the risk of error and bias. Inconsistencies between the quality assessor were discussed to reach consensus. But in most case the risk of bias for the prevalence of dental fluorosis across these studies was unjustifiable. To minimize the chance of error in data extraction, a pre-determined and standardized data extraction form was prepared and piloted with all review team members prior to the actual data extraction.

Table 1 Eligibility criteria

\begin{tabular}{ll}
\hline Inclusion criteria & Exclusion criteria \\
\hline - Country and setting: Ethiopian rift valley & - The article did not contain original data or observations \\
- Study design: Cross-sectional & - Study subjects were not humans \\
- Measurement: The concentration of fluoride in ground water and prevalence & - Fluoride concentration was not measured or estimated \\
of dental fluorosis & - Dental fluorosis was not reported using the three-severity level \\
- Types of article: Peer-reviewed and published in English language & - The mean and standard deviation of Fluoride concentration was \\
- Publication year: up to December, 2018 & not reported \\
- Undertook laboratory works: Reported type of laboratory tests and the & - Being none related to fluoride in ground water supplies and \\
respective result & dental fluorosis \\
\hline
\end{tabular}




\section{Data extraction}

Data extraction of all included papers was conducted by the three authors independently (HD, ZA and AM). These data extractors have taken practical training on the process of sourcing and recording relevant details from the primary studies included in the systematic review. Tailored Microsoft excel was used to ensure consistent data extraction, whilst reducing bias and improving validity. The following variables were extracted from studies: author, publication year, study population, water sample, number of human participants, age group and mean age of the participants, prevalence of dental fluorosis (mild, moderate and sever) and the concentrating of fluoride (minimum, maximum, mean and standard deviation in $\mathrm{mg} / \mathrm{l}$ ). But we didn't contact study authors to obtain data needed for the analysis that were not reported in the published articles. The detail characteristics of included studies are shown in (Tables 2 and 3).

\section{Data analysis}

All relevant studies which provided data on fluoride concentration in ground drinking water and crude prevalence of dental fluorosis or numbers of cases and study participants were included in the meta-analysis. Some studies reported the numerical concentration without calculating the mean fluorine concentration. In this case, the mean concentration of fluoride was calculated by summing up all concentration and divided by number of water samples. Whereas the prevalence of dental fluorosis for individual studies was determined by multiplying the ratio of dental fluorosis cases to sample size by 100.The estimation of pooled fluoride concentration and prevalence of dental fluorosis was done using CMA 2.0 and MetaXL version 5.3 software. With the assumption that true effect sizes exist between eligible studies, the random effects model was used to determine the pooled prevalence, mean fluoride and 95\% CIs. A summary (pooled) estimate is calculated as a weighted average from selected studies as follows; weighted average $=$ sum of (estimate X weight) sum of weights.

Heterogeneity was evaluated using the Cochran's Q test and $\mathrm{I}^{2}$ statistics. Significant heterogeneity was declared at $\mathrm{I}^{2}>50 \%$ and $\mathrm{Q}$-test $(P<0.10)$.

\section{Publication bias and sensitivity analysis}

The recurrence analysis under different assumptions to examine the impact of these assumptions on the results was done. Funnel plots were drawn to assess the possibility of publication bias and it indicated potential for publication bias. We plotted the studies' logit event rate and the standard error to detect asymmetry in the distribution.

\section{Heterogeneity}

The included eleven studies were assessed for heterogeneity. The differences between studies in the characteristics of their populations, in their study approaches and quality and the variation of effects between studies was checked using common sense, graphical and statistical tests. Forest plot was drawn and the overlapping confidence intervals was checked.

\section{Results}

In this review, out of 105 searched articles, 11 articles which are completely relevant to the study objectives were finally selected and the required data were extracted. To determine fluorosis severity, Dean's index was used in all studies. Water samples from ground water sources were taken at the frequency of 16 to 112 samples. The extracted data revealed that the distribution of fluoride in Ethiopian rift valley ground water varying widely ranged from 0.1 to $75 \mathrm{mg} / \mathrm{l}$. The mean fluoride concentration above $1.5 \mathrm{mg} / \mathrm{l}$ have been reported from all included studies. The daily water consumption report was available from four studies which is ranged from 0.25 to $5.0 \mathrm{l} /$ day with the pooled

Table 2 Extraction for fluoride concentration of ground drinking waters in Ethiopian rift valley

\begin{tabular}{|c|c|c|c|c|c|c|c|}
\hline \multirow[t]{2}{*}{ Author Ref } & \multicolumn{3}{|c|}{$\left[\mathrm{F}^{-}\right]$in ground water $(\mathrm{mg} / \mathrm{l})$} & \multicolumn{2}{|c|}{ Daily Water Consumption (L/d) } & \multicolumn{2}{|c|}{$\mathrm{F}$ - intake (mg/kg bw/day) } \\
\hline & Sample & Range & Mean \pm SD & Range & Mean \pm SD & Range & Mean \pm SD \\
\hline T. Rango et al. [12], 2014 & 94 & $1.1-18$ & $8.5 \pm 4.1$ & $0.33-2.7$ & $1.2 \pm 0.4$ & $0.19-0.37$ & $0.23 \pm 0.2$ \\
\hline T. Rango et al. [7], 2012 & 112 & $7.8-18$ & $10 \pm 40$ & $0.5-3.0$ & $1.2 \pm 0.34$ & $0.15-0.60$ & $0.36 \pm 0.18$ \\
\hline T. Rango et al. [11], 2017 & 27 & $0.6-15$ & $6.5 \pm 4.2$ & $0.3-5.0$ & $1.5 \pm 0.7$ & $0.005-0.94$ & $0.2 \pm 0.16$ \\
\hline Wondwossen F., et al. [14], 2004 & 30 & $0.3-14$ & $6.6 \pm 3.13$ & - & - & - & - \\
\hline Tekle-Haimanot R,. et.al [20], 2005 & 26 & $1.5-36$ & $10.0 \pm 7.8$ & - & - & - & - \\
\hline Tenalem Ayenew [22], 2008 & 51 & $0.1-75$ & $4.94 \pm 1.16$ & - & - & - & - \\
\hline Christopher J. et.al [23], 2018 & 47 & $4.8-5.2$ & $5.0 \pm 3.45$ & - & - & - & - \\
\hline Muhammed Haji,et al. [18], 2018 & 29 & $0.5-5.6$ & $2.5 \pm 1.29$ & - & - & - & - \\
\hline Tesfaw A, Feleke Z [10], 2011 & 16 & $3.2-4.19$ & $4.16+2.31$ & $0.25-3.21$ & $1.6 \pm 0.17$ & $0.25-0.31$ & $0.28 \pm 0.03$ \\
\hline Redda, Gebeyehu H [24], 2014 & 22 & $2.2-18.5$ & $9.2 \pm 4.90$ & - & - & - & - \\
\hline Aweke K.,et al. [19], 2016 & 60 & $2.6-6.5$ & $4.6 \pm 1.90$ & - & - & - & - \\
\hline
\end{tabular}


Table 3 Summary of sensitivity analysis of the included studies

\begin{tabular}{|c|c|c|c|}
\hline Excluded Studies & $\begin{array}{l}\text { Pooled mean }\left[\mathrm{F}^{-}\right] \text {in } \mathrm{mg} / \mathrm{l} \\
(95 \% \mathrm{Cl})\end{array}$ & $\mathrm{I}^{2}(95 \% \mathrm{Cl})$ & $P$-value \\
\hline T. Rango et al.,2014 [22] & $6.40[4.70,8.09]$ & $97[96,98]$ & $<0.001$ \\
\hline T. Rangoa et al.,2012 [7] & $6.16[4.75,7.58]$ & $95[93,97]$ & $<0.001$ \\
\hline Aweke K.,et al., 2016 [19] & $6.62[4.98,8.27]$ & $97[96,98]$ & $<0.001$ \\
\hline T. Rango et al.,2018 [11] & $6.64[4.88,8.39]$ & $97[96,98]$ & $<0.001$ \\
\hline Wondwossen et al.,2004 [14] & $6.63[4.85,8.41]$ & $97[96,98]$ & $<0.001$ \\
\hline Tekle-Haimanot R. et.al, 1987 [20] & $6.33[4.63,8.03]$ & $96[94,97]$ & $<0.001$ \\
\hline Tenalem Ayenew,2008 [22] & $6.86[4.61,9.11]$ & $97[96,98]$ & $<0.001$ \\
\hline Christopher J. et.al, 2018 [23] & $6.82[5.00,8.63]$ & $96[94,97]$ & $<0.001$ \\
\hline Muhammed Haji,et al.,2018 [18] & $7.10[5.50,8.70]$ & $97[96,98]$ & $<0.001$ \\
\hline Tesfaw A, Feleke Z,2011 [10] & $6.91[5.12,8.69]$ & $97[96,98]$ & $<0.001$ \\
\hline Redda, Gebeyehu H,2014 [24] & $6.36[4.65,8.07]$ & $97[96,98]$ & $<0.001$ \\
\hline
\end{tabular}

mean daily water consumption of $1.366 \mathrm{l} /$ day (95\% CI; $1.15-1.58, p<0.001)$. The results from daily Fluoride intake were also reported from four studies which is ranged from 0.005 to $0.94 \mathrm{mg} / \mathrm{Kg}$ bw/day with the pooled mean value of $0.271 \mathrm{mg} / \mathrm{Kg}$ bw/day (95\% CI; 0.22-.0.33, $\mathrm{p}<$ 0.001) (Table 2).

\section{Sensitivity analysis}

In this review, the sensitivity of each study was checked with the aim of identifying smaller or larger mean concentration reports which could affect the pooled result by giving wider confidence intervals and variance instability. But, the sensitivity analysis of this review showed no study has significantly affect the prime determinants of the pooled result (Table 3).

\section{Pooled mean fluoride concentration}

The data from eleven studies with total of 514 ground water samples in different part of Ethiopian rift valley were combined in this study. From the review, it was found that the mean fluoride concentration of the studies ranged from 2.5 to $10 \mathrm{mg} / \mathrm{l}$ with a substantial heterogeneity across studies $\left(\mathrm{Q}=492.43 ; p<0.001 ; \mathrm{I}^{2}=98 \%\right.$; 95\% CI $=97.93-98.84)$. Meta-analysis was performed based on the mean and standard deviation of the concentration of fluoride in ground drinking water resources. Since the heterogeneity was $>50 \%$, the random effect model was used to evaluate pooled fluoride concentration. The overall pooled mean concentration of fluoride in ground water of Ethiopian rift valley from random effects method was $6.03 \mathrm{mg} / 1$ (95\% CI; $4.72-$ 7.72, $\mathrm{p}<0.001$ ) which is above the WHO maximum allowable value of $1.5 \mathrm{mg} / \mathrm{L}$ (Fig. 2). Sensitivity analysis revealed no significant difference both in the pooled fluoride concentration and heterogeneity. When one study was excluded from the analysis step-by-step, the pooled mean concentration was between 6.16 and 7.10 mg/l (Table 3).

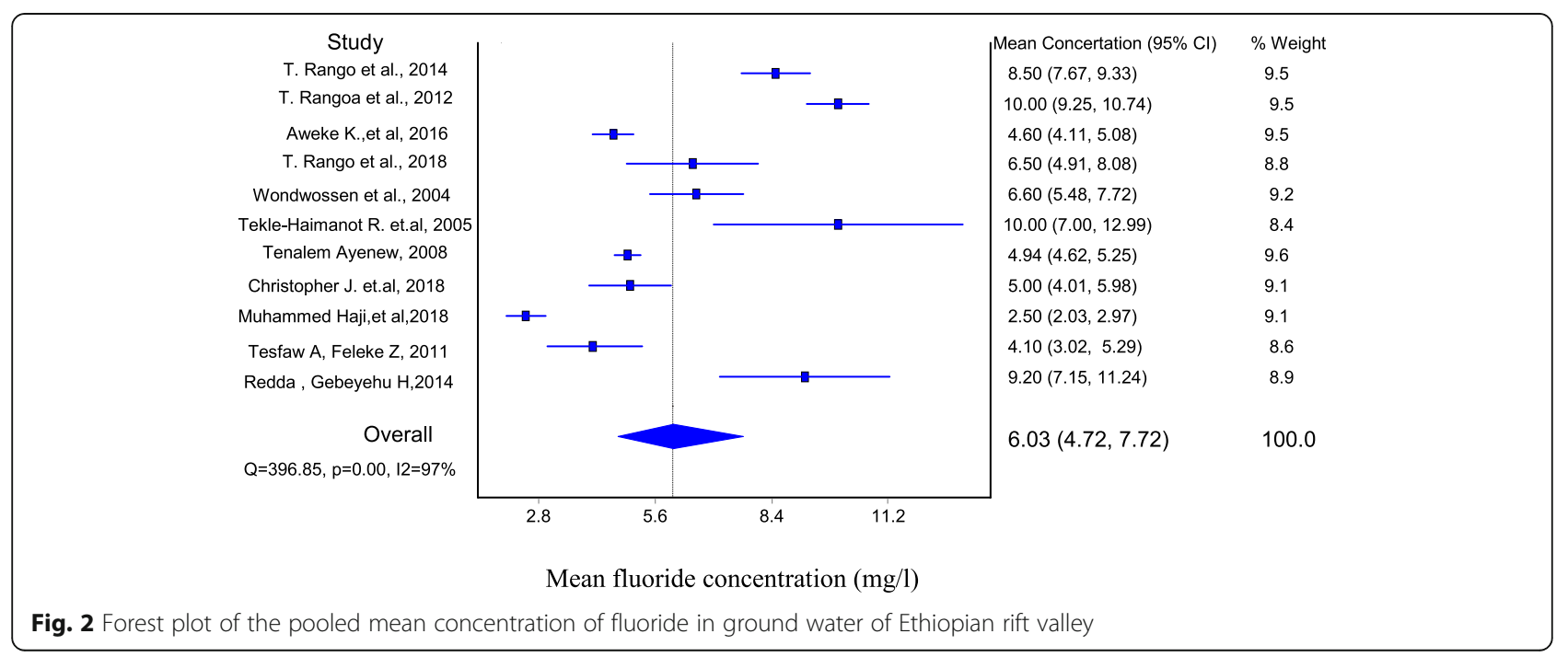




\section{Pooled prevalence of dental fluorosis}

Nine articles were selected for meta-analysis of dental fluorosis. Two articles were excluded from meta-analysis because of not reporting the prevalence and reporting of overall prevalence rather than based on different severity level. Most of the reports from primary studies were reported the prevalence of dental fluorosis as mild, moderate and sever dental fluorosis separately. This metaanalysis also made the pooled prevalence estimation with the consideration of the mild, moderate, sever and overall dental fluorosis.

The effect of other variables (exposure time, exposure to fluoride in diet and air) on the prevalence of dental fluorosis was examined in the primary studies. The temperature was also considered as a confounding factor, which has been included in a few studies.

A total of 4852 residents were participated in the study in the age range of 7 to 50-year-old (Table 4). The pooled prevalence of dental fluorosis among residents in Ethiopian rift valley was estimated to be 32\% (95\% CI: $25,39 \%, p<0.001)$ for mild dental fluorosis, $29 \%$ (95\% CI: $22,36 \%, \mathrm{p}<0.001)$ for moderate dental fluorosis and $24 \%$ (95\% CI: $17,32 \%, \mathrm{p}<0.001$ for sever dental fluorosis. The overall prevalence of dental fluorosis is $28 \%$ (95\% CI: 24, 32\%, $p<0.001$ ) (Fig. 3).

During the sensitivity analysis, when one study was excluded from the analysis step-by-step, the pooled prevalence of dental fluorosis was between 35 and $41 \%$, for mild, 30 and 35\% for moderate and 25 and 33\% for sever dental fluorosis prevalence.

\section{Discussion}

From this review, it was estimated that the mean fluoride concentration in ground drinking water of Ethiopian rift valley is high above the WHO standard $(1.5 \mathrm{mg} / \mathrm{l})$. Such elevated fluoride in drinking water sources gives the picture of severity of fluoride problem in Ethiopian rift valley with varies health risks associated with high fluoride concentration.

According to the research report in India [27], the mean concentration of fluoride in ground drinking water was lower than Ethiopian rift valley mean value. Similarly, other studies on fluoride content in ground drinking water in Iran $[28,29]$, revealed lower mean concentration than the fluoride concentration in Ethiopian rift valley ground water. The difference might be the effect of the east African rift valley which is known with active volcanic eruption resulting fluoride release and availability of different water sources for drinking in another part of the world.

Study reports from Kenyan Rift Valley revealed fluoride concentration level of $11 \mathrm{mg} / \mathrm{L}$ which is greater than this research result and Tanzanian rift valley, showed the fluoride concentration levels of $4.6 \mathrm{mg} / \mathrm{L}$ which is less than the pooled mean concentration of this research [30, 31]. According to a systematic review and metal analysis conducted in other African countries, the fluoride concentration in Uganda, South Africa, Gahna, Nigeria and Tanzania was $\quad 0.74 \mathrm{mg} / \mathrm{L}, 1.27 \mathrm{mg} / \mathrm{L}, \quad 2.09 \mathrm{mg} / \mathrm{l}, 1.44 \mathrm{mg} / \mathrm{l}$ and $5.08 \mathrm{mg} / \mathrm{l}$ respectively [4]. All fluoride level in ground water source of the above African countries was lower than this pooled mean concentration of fluoride in Ethiopian rift valley except the mean concentration value in Kenya. The difference might be due to sample size and sampling techniques of the primary research and the characteristics of the geographical location of the region.

Though, the concentration level varies across different part of the rift valley region, still the level of fluoride in ground drinking water is greater than the WHO standard value. Other important measurements of fluoride exposure like the estimated daily fluoride intake per day and fluoride intake per body weight per day are more informative to assess the risk of fluoride concentration in ground water. But these are not discussed in detail in this report due to absence and incomplete report from primary studies.

Table 4 Extraction for prevalence of dental fluorosis based on its severity among the understudy samples in Ethiopian rift valley

\begin{tabular}{|c|c|c|c|c|c|c|}
\hline \multirow[t]{2}{*}{ Author Ref } & \multirow[t]{2}{*}{ Sample } & \multirow{2}{*}{$\begin{array}{l}\text { Age } \\
\text { range }\end{array}$} & \multirow[t]{2}{*}{ Mean \pm SD } & \multicolumn{3}{|c|}{ Prevalence of dental fluorosis } \\
\hline & & & & Mild & Moderate & Sever \\
\hline T. Rango et al. [12], 2014 & 491 & $10-15$ & $12.1 \pm 1.6$ & 17 & 29 & 45.00 \\
\hline T. Rango et al. [7], 2012 & 200 & $7-40$ & $16.0 \pm 6.2$ & 30 & 52 & 8.40 \\
\hline T. Rango et al. [11], 2018 & 386 & $10-50$ & $24.5 \pm 11.1$ & 21.7 & 20.4 & 34.10 \\
\hline WondwossenF.,et al. [14], 2004 & 306 & $12-15$ & $13.5 \pm 2.1$ & 47 & 28 & 20.00 \\
\hline Tekle-Haimanot et.al [20], 2005 & 1456 & $7-20$ & $13.2 \pm 2.4$ & 28 & 21 & 35.00 \\
\hline Frank van S et al. [25], 2011 & 625 & $10-15$ & $13.2 \pm 1.8$ & 42 & 15.36 & 5.00 \\
\hline Tesfaw A, Feleke Z [10], 2011 & 118 & $10-15$ & $12.1 \pm 1.5$ & 27.9 & 38.1 & 22.00 \\
\hline Aweke K.,et al. [19], 2016 & 216 & $10-15$ & $12.4 \pm 1.7$ & 32.1 & 18.87 & 4.47 \\
\hline Kravchenko J, et al. [26], 2014 & 1054 & $10-30$ & $13.1 \pm 1.9$ & 37.6 & 39 & 23.40 \\
\hline
\end{tabular}




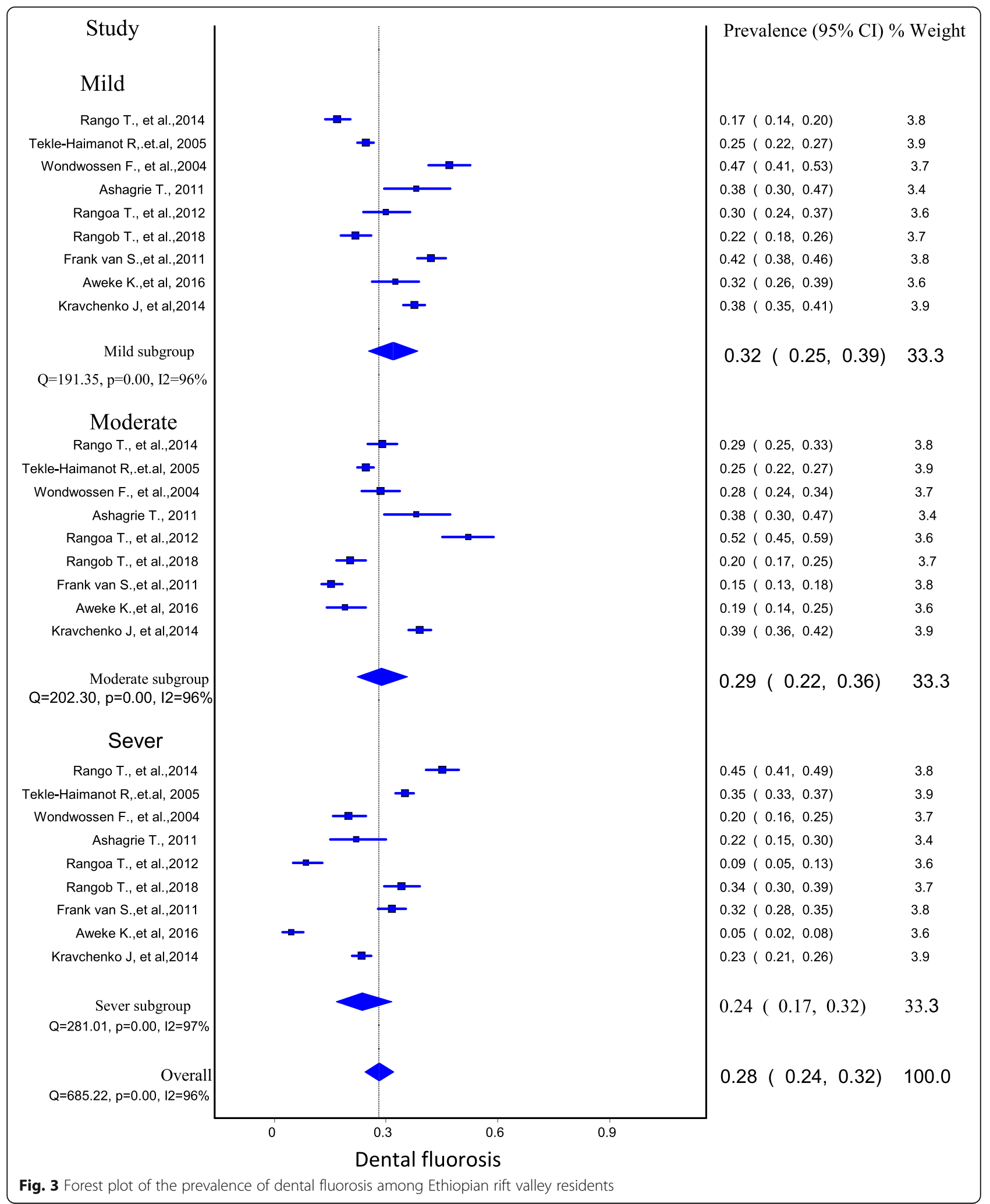

The pooled prevalence of dental fluorosis among 4852 Ethiopian rift valley residences was estimated to be $28 \%$ ranging from 24 to $32 \%$. Studies reported high prevalence of dental fluorosis in the Rift Valley region of Ethiopia where the level of fluoride, especially in groundwater is significantly high $[14,17,20]$. Evidences from other studies also indicated 
that dental fluorosis is well recognized health problem $[2,4$, $8,32]$. According to the systematic review conducted in India, the pooled estimation of dental fluorosis was reported as $12.9 \%$ [33], which is much more lower than this result. Another study in Iran revealed the prevalence of dental fluorosis was $61 \%$ [34],which is more than the pooled estimation of this review.

According to a systematic review and meta-analysis in Iran, the pooled prevalence of dental fluorosis was 52.6\% [8]. The study conducted in Tanzanian sector of the east African rift valley among 1434 children in the age range of 12-18 years, the prevalence of dental fluorosis was reported as $85.3 \%$ for mild, $75 \%$ for moderate and $41.4 \%$ for sever fluorosis [31] which is significantly greater than this review result.

The reported prevalence of dental fluorosis among 1549 participants in Ethiopian rift valley was estimated to be $70 \%$ for mild and $48.2 \%$ for sever [3]. The potential difference in the prevalence of dental fluorosis from the current pooled value might be due to the fact that weighted value for meta-analysis is likely affected by different factor from primary studies and application of different interventions in the area.

\section{Conclusion}

This is the first systematic review and meta-analysis of the literature on the level of fluoride concentration in ground water and the prevalence of dental fluorosis in Ethiopian sector of East African rift valley. It is found that the pooled mean concentration of fluoride in ground drinking water and the pooled prevalence of dental fluorosis among residents in Ethiopian rift valley is expectedly high. Because the East African Rift Valley which cuts through Ethiopia is geomorphologically still an active volcanic region. It is also supported with other evidences from different part of East African rift valley. Since East African Rift Valley is still an active volcanic region, fluoride concentration is expected at high level in ground water for the future. Therefore, to address the health impact of high fluoride concentration in ground drinking water source of Ethiopian rift valley, use of alternative sources of drinking water as well as appropriate defluoridation technique is recommended. In addition, educating the community on dangers of using water with excess fluoride is recommended in order to ensure good health. The effort to establish long term trend of fluoride concentration in water should also be taken in consideration. This helps to predict future concentration of fluoride and possibility to minimize future risks. Comparative studies across different part of the rift valley to identify the priority area for intervention will helpful.

\section{Limitations}

Only cross-sectional studies were included which are providing only snapshots of the situation at a particular moment in time and fail to capture the seasonal nature of the fluoride concentration in ground water. The number of primary studies for estimation of the pooled mean fluoride concentration and dental fluorosis were decreased (only eleven studies). In addition, this study was based only on published peer-reviewed in English language studies and important data might be missed from unpublished and published in other language studies and grey publications.

\section{Abbreviations \\ Cl: Confidence interval; ISE: Ion selective electrode; L: Liter; Mg: Milligram; TF: Thylstrup and Fejerskov}

\section{Acknowledgements}

Not applicable

\section{Declarations}

Not applicable

\section{Authors' contributions}

$\mathrm{HD}$ conceived the design, interpret the findings and wrote the manuscript. $A B, Z A a n d ~ A M$ select and assess quality of studies, extract data, interpret result, and review the manuscript. All authors read and approved the manuscript.

\section{Funding}

We author declared that we did not receive funding for this research from any source.

Availability of data and materials

All data generated or analyzed are included in the results of the manuscript.

Ethics approval and consent to participate

Not applicable

Consent for publication

Not applicable.

\section{Competing interests}

The authors declare that they have no competing interests.

\section{Author details}

${ }^{1}$ College of Health Sciences, Department of Public Health, Debre Tabor University, Debre Tabor, Ethiopia. ${ }^{2}$ Institution of Health, Department of Environmental Health Science and Technology, Jimma University, Jimma, Ethiopia. ${ }^{3}$ College of Natural and computational Sciences, Department of Chemistry, Debre Markos University, Debre Markos, Ethiopia. ${ }^{4}$ College of Medicine and Health Sciences, Department of medical laboratory science, Bahir Dar University, Bahir Dar, Ethiopia.

Received: 22 July 2019 Accepted: 20 September 2019

Published online: 16 October 2019

\section{References}

1. Organization WH. Inadequate or excess fluoride: a major public health concern. Geneva: WHO Public Health and Environment; 2010.

2. Fawell J, Bailey K, Chilton J, Dahi E, Magara Y. Fluoride in drinking-water: IWA publishing; 2006.

3. Kloos H, Haimanot RT. Distribution of fluoride and fluorosis in Ethiopia and prospects for control. Trop Med Int Health. 1999;4(5):355-64.

4. Malago J, Makoba E, Muzuka AN. Fluoride levels in surface and groundwater in Africa: a review. Am J Water Sci Eng. 2017;3(1):1-17. 
5. van Steenbergen F, Haimanot RT, Sidelil A. High Fluoride, Modest Fluorosis: Investigation in Drinking Water Supply in Halaba (SNNPR, Ethiopia). J Water Resour Prot. 2011;03(02):120-6. https://doi.org/10.4236/jwarp.2011.32014.

6. Petersen PE, Kwan S. Evaluation of community-based oral health promotion and oral disease prevention-WHO recommendations for improved evidence in public health practice. Community Dent Health. 2004;21(4):319-29.

7. Rango T, Kravchenko J, Atlaw B, McCornick PG, Jeuland M, Merola B, et al. Groundwater quality and its health impact: an assessment of dental fluorosis in rural inhabitants of the Main Ethiopian Rift. Environ Int. 2012:43:37-47.

8. Goodarzi F, Mahvi AH, Hosseini M, Nodehi RN, Kharazifard MJ, Parvizishad M. Fluoride concentration of drinking water and dental fluorosis: a systematic review and meta-analysis in Iran. Dental Hypotheses. 2016;7(3):81.

9. Amini M, Mueller K, Abbaspour KC, Rosenberg T, Afyuni M, Møller KN, et al. Statistical modeling of global geogenic fluoride contamination in groundwaters. Environ Sci Technol. 2008;42(10):3662-8.

10. Ashagrie T. Total dietary fluoride intake and its observed health effect in young children: case of Bidara Fuka and Dibibisa Kebeles in SNNPR and Oromia regions; Ethiopian Rift Valley; 2011.

11. Rango T, Vengosh A, Jeuland M, Whitford GM, Tekle-Haimanot R. Biomarkers of chronic fluoride exposure in groundwater in a highly exposed population. Sci Total Environ. 2018;596:1-11.

12. Rango $T$, Vengosh $A$, Jeuland $M$, Tekle-Haimanot $R$, Weinthal $E$, Kravchenko J, et al. Fluoride exposure from groundwater as reflected by urinary fluoride and children's dental fluorosis in the Main Ethiopian Rift Valley. Sci Total Environ. 2014;496:188-97.

13. Dey S, Giri B. Fluoride fact on human health and health problems: a review. Med Clin Rev. 2016;2(1-2):1-6.

14. Wondwossen F, Åstrøm AN, Bjorvatn K, Bårdsen A. The relationship between dental caries and dental fluorosis in areas with moderate-and high-fluoride drinking water in Ethiopia. Community Dent Oral Epidemiol. 2004;32(5):337-44

15. Dessalegne M, Zewge F. Daily dietary fluoride intake in rural villages of the Ethiopian Rift Valley. Toxicol Environ Chem. 2013;95(6):1056-68.

16. Ramadan A, Ghandourb I. Dental fluorosis in two communities in Khartoum state, Sudan, with potable water fluoride levels of 1.36 and $0.45 \mathrm{mg} / \mathrm{L}$ Fluoride. 2016;49(4):509-20.

17. Tekle-Haimanot R, Fekadu A, Bushera B, Mekonnen Y, editors. Fluoride levels in water and endemic fluorosis in Ethiopian Rift Valley. International Workshop on Fluorosis and Defluoridation of Water; 1995.

18. Haji M, Wang D, Li L, Qin D, Guo Y. Geochemical Evolution of Fluoride and Implication for Fân Enrichment in Groundwater: Example from the Bilate River Basin of Southern Main Ethiopian Rift. Water. 2018;10(12):1799.

19. Kebede A, Retta N, Abuye C, Malde M. Community knowledge, attitude and practices (KAP) on fluorosis and its mitigation in endemic areas of Ethiopia. Afr J Food Agric Nutr Dev. 2016;16(1):10711-22.

20. Tekle-Haimanot R, Melaku Z, Kloos H, Reimann C, Fantaye W, Zerihun L, et al. The geographic distribution of fluoride in surface and groundwater in Ethiopia with an emphasis on the Rift Valley. Sci Total Environ. 2005;367(1):182-90.

21. Moher D, Liberati A, Tetzlaff J, Altman DG. Preferred reporting items for systematic reviews and meta-analyses: the PRISMA statement. Ann Intern Med. 2009;151(4):264-9.

22. Furi W, Razack M, Abiye TA, Ayenew T, Legesse D. Fluoride enrichment mechanism and geospatial distribution in the volcanic aquifers of the middle awash basin, northern Main Ethiopian rift. J Afr Earth Sci. 2008; 60(5):315-27.

23. Christopher J, Paul MAJ, Tewodros R. Godebod, Erika Weinthale communities coping with risks: household water choice and environmental health in the Ethiopian Rift Valley. Environ Sci Policy. 2018;86:85-94.

24. Redda T-H, Gebeyehu H. Chronic alcohol consumption and the development of skeletal fluorosis in a fluoride endemic area of the Ethiopian Rift Valley. J Water Resour Prot. 2014;6:149.

25. van Steenbergen F, Haimanot RT, Sidelil A. High Fluoride, Modest Fluorosis: Investigation in Drinking Water Supply in Halaba (SNNPR, Ethiopia). J Water Resour Prot. 2011;3:120-6.

26. Alemu ZA, Mengesha SD, Alemayehu TA, Serte MG, Kidane AW, Teklu KT. Retrospective Study of Fluoride Distribution in Ethiopian Drinking Water Sources. Asian J Appl Sci Eng. 2015;4(2):127-36.

27. Golgire G, Shetti S, Patil A, Khairnar M, Varekar A. Estimation of Fluoride Level in Drinking Water and Prevalence of Dental Fluorosis in Vairag Village of Solapur District, Maharashtra, India: A Cross Sectional Study. Epidemiology (Sunnyvale). 2016;6(275):2161-1165.1000275.

28. Keshavarz S, Ebrahimi A, Nikaeen M. Fluoride exposure and its health risk assessment in drinking water and staple food in the population of Dayyer, Iran, in 2013. J Educ Health Promot. 2015;4:72.

29. Aghapour S, Bina B, Tarrahi MJ, Amiri F, Ebrahimi A. Distribution and health risk assessment of natural fluoride of drinking groundwater resources of Isfahan, Iran, using GIS. Environ Monit Assess. 2018;190(3):137.

30. Nyanchaga EN, Bailey T. Fluoride contamination in drinking water in the Rift Valley, Kenya and evaluation of the efficiency of a locally manufactured defluoridation filter. J Civil Eng JKUAT. 2003;8(1):79-88.

31. Vuhahula E, Masalu J, Mabelya L, Wandwi W. Dental fluorosis in Tanzania great Rift Valley in relation to fluoride levels in water and in â€ Magadiâ $€^{\text {TM}}$ (Trona). Desalination. 2009;248(1-3):610-5.

32. Avocefohoun S, Gbaguidi A, Sina H, Biaou O, Houssou S, Baba-Moussa L. Fluoride in water intake and prevalence of dental fluorosis stains among children in Central Benin. Int J Med Res Health Sci. 2017;6(12):71-7.

33. Goodarzi F, Mahvi AH, Hosseini M, Nedjat S, Nodehi RN, Kharazifard MJ, et al. The prevalence of dental fluorosis and exposure to fluoride in drinking water: A systematic review. J Dent Res Dent Clin Dent Prospects. 2016;10(3):127.

34. Azami-Aghdash S, Ghojazadeh M, Azar FP, Naghavi-Behzad M, Mahmoudi M, Jamali Z. Fluoride concentration of drinking waters and prevalence of fluorosis in iran: a systematic review. J Dent Res Dent Clin Dent Prospects. 2013;7(1):1.

\section{Publisher's Note}

Springer Nature remains neutral with regard to jurisdictional claims in published maps and institutional affiliations.
Ready to submit your research? Choose BMC and benefit from:

- fast, convenient online submission

- thorough peer review by experienced researchers in your field

- rapid publication on acceptance

- support for research data, including large and complex data types

- gold Open Access which fosters wider collaboration and increased citations

- maximum visibility for your research: over $100 \mathrm{M}$ website views per year

At BMC, research is always in progress.

Learn more biomedcentral.com/submissions 